Sharif University of Technology
Scientia Iranica
SCIENTIA
I RAN I C A

\title{
Applying resilience thinking to select more sustainable urban development scenarios in Shiraz, Iran
}

\author{
A. Sotoudeh ${ }^{\mathrm{a}, *}$ and P. Parivar ${ }^{\mathrm{b}}$ \\ a. Department of Environment, Faculty of Natural Resources and Desert Studies, Yazd University, Yazd, Iran. \\ b. Graduate Faculty of Environment, University of Tehran, Tehran, Iran. \\ Received 1 February 2015; received in revised form 4 December 2015; accepted 27 February 2016
}

\section{KEYWORDS \\ Resilience thinking; Ecological health; Imperviousness index; Urban development; Landscape metrics.}

\begin{abstract}
Rapid urbanization is among the most important causes of ecological degradation across different spatial scales ranging from global to regional and local. As protection of ecological health and resiliency has a profound effect on human being and welfare, it is essential for planners to incorporate ecological considerations into landscape and urban planning in order to realize wiser management of the future changes in harmony with sustainable development goals. This research introduces an approach to combine imperviousness indicator with landscape metrics to provide quantitative information on the spatiotemporal dynamics of Shiraz region. Landsat images are used to map the land cover of Shiraz region in 1976, 1990, 2000, and 2005. Using landscape metrics, spatial composition and configuration of impervious surface have been quantified. The metrics indicated increase in the size and connectivity of impervious surfaces. Results reveal that the growth of urbanization has had tremendous effects on the size and connectivity of natural landscapes, particularly agricultural areas and wetlands. Furthermore, two urban growth scenarios have been generated for the year 2021 using modeling and compared using the aforesaid indices. The results point out that smart growth scenario, in which the land is efficiently used, is ecologically a more resilient option.

(C) 2016 Sharif University of Technology. All rights reserved.
\end{abstract}

\section{Introduction}

Changes to the characteristics of land cover appear to be one of the most crucial factors in the destruction of the earth's ecosystems which is caused by human intervention in ecosystem function. Over the past decades, such interventions have radically altered the face of the earth. As one of the main causes of such alteration, urbanization has shown a growing trend and it will, undoubtedly, continue through the twenty-first century. In 1950 , only 29 percent of the world's population of 2.5 billion was urban dwellers; but in 2008, for the first time in history, more than

*. Corresponding author. Fax: +98 3538210312 E-mail addresses: a.sotoudeh@yazd.ac.ir (A. Sotoudeh); Parivar.p@gmail.com (P. Parivar) half the population of 6.6 billion people lived in cities [1].

As a result of the growth in urban population, cities are physically expanded and natural landscapes have been destroyed. In fact, precipitous urbanization has been identified as a critical phenomenon that leads to a complete transformation in the ecological structure and functions of the landscapes. Also, with regard to the decisions made related to land use change in urban regions, we experience impacts such as structure changing, fragmentation, isolation of natural habitats [2], hydrological system failure [3], and changes of energy flow and food cycle [4], as well as loss of farmland [5] and food security [6]; all these changes lead to reduction in ecological resilience in different spatial scales and makes urban systems increasingly vulnerable [7]. 
Ecological resilience is actually the basic capacity that an ecosystem has to maintain satisfying services when confronted with environmental changes and human exploitation [8]. Furthermore, another definition indicates the capacity of the ecological and social systems to attract disorders for maintaining necessary and inherent system feedback, functions, and structures [9].

Understanding the changes in ecological resilience caused by urban development is very important to urban planners and also resource managers. Since examining the process of changes of land cover into urban lands and identifying the parameters effective in this process play a major role in decision making and planning, predicting the process of urban development in future by accurate and efficient methods such as predictive models of urban development proves to be more essential than ever.

In recent years, the concept of resilience has been applied to urban studies by researchers, urban planners, and local governments [10]. Resilience thinking is a structured method that can be used for consideration of complications, uncertainties, and internal relations and processes of systems; it also provides the condition for new planning methods and efficient application of assessment $[11,8]$. Employing resilience thinking, which is based on a mutual relationship between structure and function [2] and offers the possibility of examining the dynamics of ecological processes in temporal-spatial scales, might be helpful for urban planning. The application of resilience thinking can also be seen more generally in scenario planning or other techniques that explicitly acknowledge the uncertainty inherent in planning for the future [12].

To identify the resilience of each ecological system, ecological indicators need to be employed to measure all aspects of the ecological system. Accordingly, we should identify indicators which are applicable, meaningful, and low-cost and use them to monitor the past, present, and future status of the ecological systems [13]. According to the emphasis of resilience thinking on understanding of the relationship between structure and function, use of structural indicators to monitor changes in ecological processes is essential $[2,14]$.

Regarding urban ecological structure, impervious surface coverage has long been used as a reliable indicator for examining the quality of environment in urban zones [3]. Impervious surface coverage can be defined as any coverage which prevents the infiltration of water into the soil. The most known covers are roads, buildings, parking lots, and sidewalks. The more we alter the development of lands, the more we increase the degree of imperviousness. The most important ecological impacts of impervious surface due to urban development include habitat degradation, loss, and fragmentation; removal of natural storage, retention, and recycling of precipitation; decrease in stream base flow and groundwater recharge; increase in the magnitude and frequency of flooding; and changes to local energy balances and microclimates [3]. In addition to the environmental effects of the development of imperviousness, it is also considered to be an indicator of human presence in environment. The expansion of road networks as an impervious surface is a good example of this issue - making it more accessible for humans to reach natural lands.

Imperviousness can be measured through field work and satellite and areal images. Over the past decades, advances in remote sensing have made this index one of the cheapest, simplest, and most applicable indicators in planning. By measuring spatial composition and configuration of impervious surfaces of urban landscapes in different periods of time, we can gain a better understanding of relationship between ecological structure and functions and resiliency of urban landscapes to these structural transformation caused by urban development.

Because urban development acts as the main driving force of change in ecological structure and functions, we need credible scenario-based land-cover simulation models to assess the impacts of future scenario of urban development on ecological resiliency of background landscapes. To achieve simulation modeling of future scenarios, detailed data of socioeconomic, ecological, and land cover change must be considered in these models.

One of the scenarios of urban development that has recently been emphasized in many cities of the world is smart growth scenario. Smart urban growth, with its ten principles, strives to make cities more sustainable. Implementing such an idea seems to not only provide better urban accessibility, energy saving, decrease in environmental pollutions, and waste recycling, but also prevent the loss of non-renewal environmental resources such as farmlands and open spaces and diminish the impacts of urban development on destruction and disruption of habitats [15]. Another scenario that must be considered to judge against smart growth is growth of urban area same as current growth rate and behavior. Both of these scenarios are considered to be close to reality. Scenario modeling makes it possible for planners and decision makers to easily compare the impacts of urban development scenarios on ecological resilience by using impervious surfaces as a reliable indicator.

The objective of this paper is to address the above-mentioned challenges and to develop methods for integration of ecological resilience issues in urban planning using a combination of spatial metrics and future land cover simulation modeling in an urbanizing landscape. The main research question addressed in this paper is: "which scenario of urban development 
is more sustainable based on the ecological resiliency indicators?" In order to answer this question, a methodology has been developed and a case study carried out to demonstrate the application of resilience thinking in selection of more sustainable scenarios of urban development.

\section{Materials and methods}

In this study, urban region of Shiraz has been selected as the study area. As a metropolitan city in Iran, Shiraz has undergone a rapid population growth over the past decades and the projections point out an exorbitantly rapid population growth in its urban areas over the next years. Population growth will result in a change in the land cover and an increase in the impervious surfaces in the entire urban region, thereby increasing the environmental effects. Investigating land dynamics over the next decades using impervious index and spatial metrics can, therefore, provide the managers and planners with a better understanding of planning of future programs for urban development in Shiraz. Shiraz is located in the southern subdistrict of Zagros in south of Iran. Its urban region is built at the foot of Zagros Mountains, extending from the north-west to the south-east. Regarding the hydrological consideration, it is located in Maharlu Basin with the minimum and maximum heights of 1470 and 3000 meters, respectively. With respect to its climatology, this urban region has the average temperature of 17.5 Celsius, the average rainfall of 392 millimeters, and a cold semi-arid climate in the De Martonne classification index. The entire region is roughly 2200 square kilometers in Maharlu Basin (Figure 1). Shiraz has a population of 1227331 [16] and it has witnessed a rapidly increasing population over the past decades (Figure 2).

Urban region of Shiraz inclines, parallel to Zagros mountain ranges, from the north-west to the southeast. Khoshk River is the only seasonal river in this urban region, which is responsible for drainage and

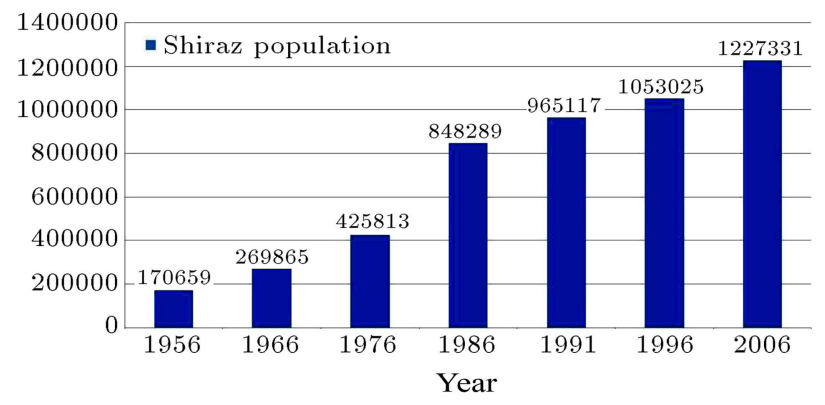

Figure 2. Shiraz population growth from 1956 to 2006.

leading water, particularly during high rainfall season, to Maharlu Lake.

The precipitous growth in urban region of Shiraz has caused a number of habitats and farmlands to undergo a land use transformation into industrial and residential areas, consequently causing environmental problems such as habitat degradation, air pollution, water pollution, and a decline in the capacity of refining and absorbing pollutants and ecological services, in general. In this regard, measures need to be taken in planning and directing urban development by taking ecological approaches into consideration and urban development direction plans need to be formulated in different strategic and operational levels by considering the physical and environmental features of the urban region through modifying the landscape structure.

\subsection{Creating land cover map using satellite images}

Landsat images and digital topographic map have been used to investigate the changes of impervious surfaces. The Landsat images have the advantages of wide and panoramic vision, and multi-spectral and covering repetitive images in different periods of time. These satellite images meet the needs of the study (providing land cover map and identifying impervious surfaces). For producing land cover map, firstly, regarding the location of urban region of Shiraz which, according to Landsat satellite index, is situated within 4 different scenes of $162-39,162-40,163-39$, and $163-$

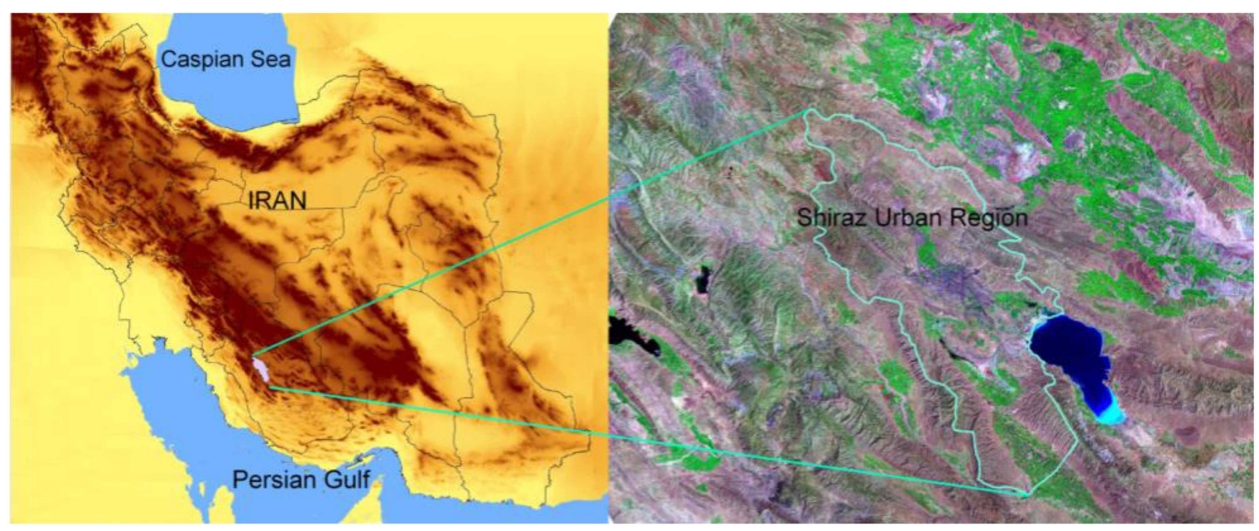

Figure 1. The location of urban region of Shiraz. 

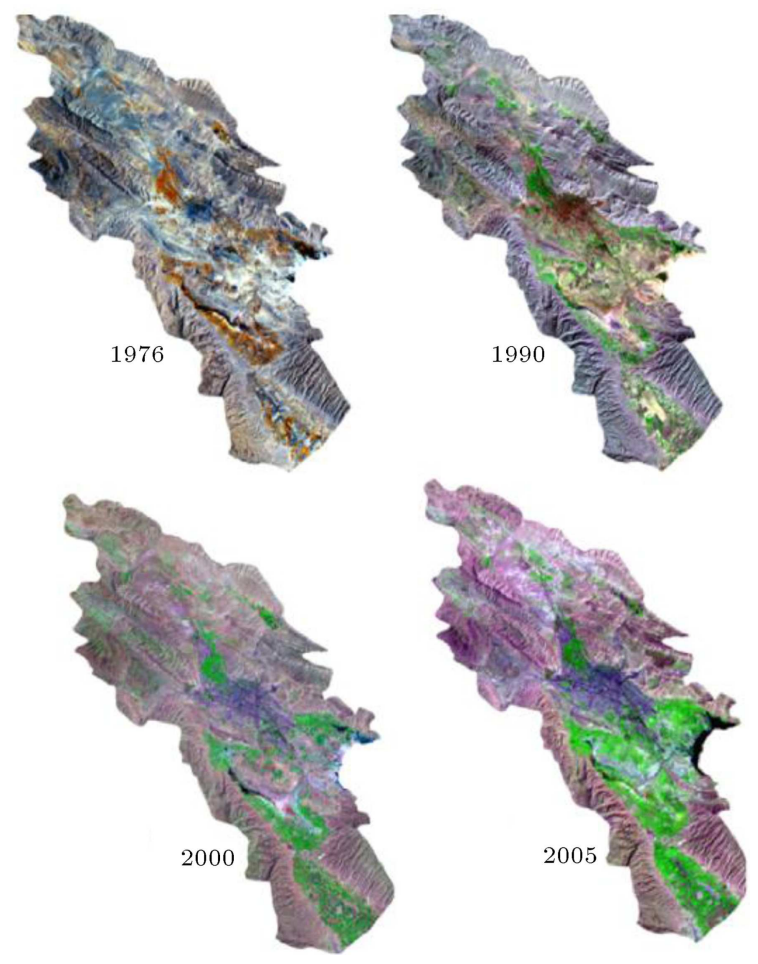

Figure 3. Landsat images of Shiraz in 1976, 1990, 2000, and 2005 .

40, the satellite images concerning these 4 scenes in 4 different periods of time (1976, 1990, 2000, and 2005) were downloaded from United States Geological Survey website (USGS) (Figure 3).

After the provision of satellite data, in order to prepare the data to be processed and to extract efficient information, geometrical correction of images was carried out using ground control point method. Resampling was conducted using the Nearest Neighbor method (NN) and all of the bands were geometrically rectified through the use of NN method. Spectral rectification of images was performed in order to clarify the phenomena, improve the quality of images, and eliminate the adverse effects of light and atmosphere in images. Land covers were then classified and impervious surfaces were extracted using decision tree method. Decision tree not only has the advantage of accessing the spectral data of different bands, but also allows using other sources of information in classifications. In this method, various phenomena are separated in an orderly fashion by using different bands of satellite images or other digital information. Through the use of this method, green areas containing green vegetation were initially identified using Normalized Difference Vegetation Index (NDVI) and water surfaces such as lakes and wetlands were then identified by using infrared band. In the next phase, through visual interpretation and determining the threshold level for spectral reflectance, constructed and open surfaces were identified. Ultimately, by using the

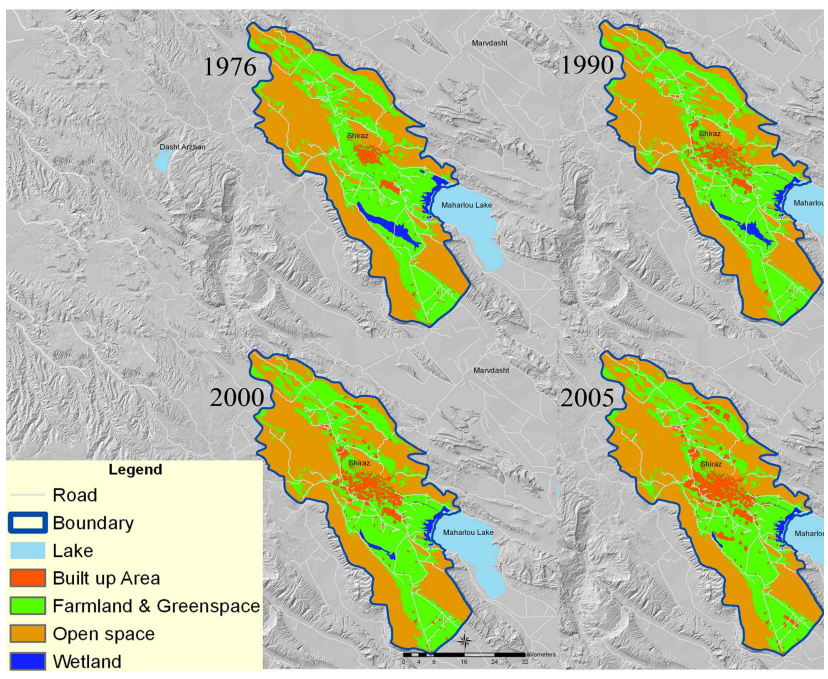

Figure 4. Landcover maps of Shiraz urban region in 1976, 1990, 2000, and 2005.

slope map, lands with a slope of more than $20 \%$, which lacked constructed surfaces, were considered as open spaces. After the classification, land cover maps of Shiraz in four different years were produced. Regarding the purpose of the study and the types of region's land cover, 4 different classes were identified: man-made impervious surfaces (built-up area), open spaces, farmlands and green spaces, and wetlands and water surfaces (Figure 4). In interpreting the data, topographic data of maps in scale of 1:25000 and the experiences based on field work were also used. Finally, the land cover maps were checked for accuracy by field study and using error matrix method.

\subsection{Modeling different scenarios}

Uplan model [17] was used in order to predict urban growth in Shiraz. Two scenarios were defined in this research. The first scenario, here referred to as "the status quo" or current growth, simulates urban builtup area, using the current growth data along with criterion maps, and the built up area development for 2021 is simulated. The other scenario takes smart growth criteria into account. Smart urban growth, with its ten principles, strives to make cities more sustainable. Implementing such an idea seems to not only provide better urban accessibility, energy saving, decrease in environmental pollutions, and waste recycling, but also prevent the loss of non-renewal environmental resources such as farmlands and open spaces and diminish the impacts of urban development on destruction and disruption of habitats [15]. Modeling smart growth scenario has been applied based on compact city pattern and also consolidated by using urban ecological capability evaluation model [18] and protection of vulnerable habitats such as wetlands.

According to master plan's projection, the population of Shiraz will reach 1750000 by 2021. Finally, 
several steps were implemented toward achieving research objectives:

- Obtaining data layers of slope, roads, wetlands, farmlands, protected areas, non-developmental regions, and current land use;

- Converting data layers into raster format;

- Obtaining statistical data of the region, such as launch year population and target year population, household size, number of employed people in each family, mean area of each house, launch year employment rate, and target year employment rate;

- Slotting raster maps and statistical data into Uplan model;

- Introducing attraction and discouragement layers for each scenario (Figure 5(a) and (c));

- Introducing non-developmental layers into the model;

- Implementing the model.

After implementing the model, two urban growth scenarios in Shiraz were prepared (Figure 5(b) and (d)).

\subsection{Employing landscape metrics}

Quantitative description of landscape appears to be the prerequisite of studying landscape function and its structural changes. In doing so, various metrics are used in landscape ecology [19].

Landscape metrics describe spatial structure of the landscape as a complex whole having a distinctive character in a specific period of time. They are beneficial in obtaining a primary classification of landscape patterns and also in bringing the language of urban planners and ecologists together [14]. With regard to the issue in focus, spatial metrics can be analyzed in patch, class, and landscape levels.

In this research, six spatial metrics were used including: Class Area (CA), percentage of landscape (PLAND), Number of Patches (NP), area weighted mean (AREA_AM), radius of gyration (GYRATE), and Euclidean Nearest Neighbor (ENN). The selection of the metrics was based on their potentiality for explaining the spatial composition and configuration of landscape structural elements.

CA metric (Class Area) simply measures each class of landscape cover in hectares. PLAND metric

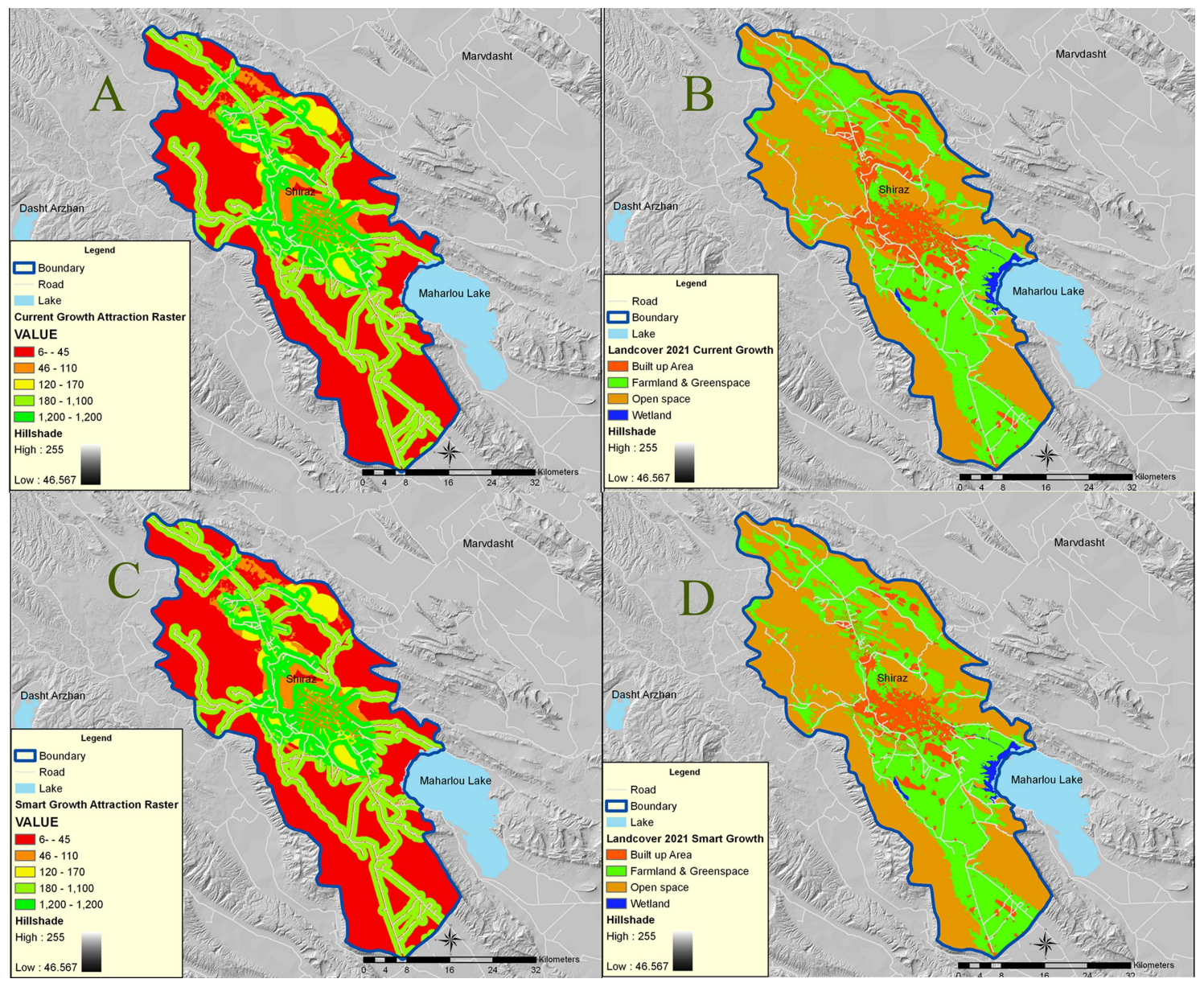

Figure 5. Attraction map in urban growth projection model and projected land cover for two scenarios 2021: (a) \& (b) Assuming current growth scenario; and (c) \& (d) assuming smart growth scenario. 
Table 1. Class-level metrics of impervious surfaces for different years and two scenarios of current growth and smart growth.

\begin{tabular}{ccccccc}
\hline Year & CA & PLAND & NP & AREA_AM & GYRATE_AM & ENN_AM \\
\hline 1976 & 5478.66 & 2.486 & 650 & 1515.132 & 1465.916 & 234.3122 \\
1990 & 11312.73 & 5.1337 & 1040 & 2352.49 & 1987.1 & 82.1841 \\
2000 & 15013.53 & 6.8131 & 1144 & 4476.096 & 2866.727 & 80.6345 \\
2005 & 19548.54 & 8.871 & 975 & 6952.782 & 3578.708 & 116.0306 \\
Smart growth scenario & 20659.32 & 9.3752 & 2163 & 6685.577 & 3435.506 & 103.7735 \\
Current growth scenario & 27618.93 & 12.5334 & 2727 & 11832.94 & 4834.927 & 91.2659 \\
\hline
\end{tabular}

(percentage of class area) calculates percentage of the landscape that consists of one type of land cover. PLAND is a measure of landscape composition and shows the ratio of a land cover class area to the whole landscape irrespective of its spatial configuration. This metric describes a major aspect of landscape structure and is, in a sense, the most important metric in explaining the landscape. This metric is able to show land matrix, the biggest patch of the landscape, and also small patches that although are small in area, they are ecologically important. When the landscape consists of one land cover class, PLAND value is 100 and when its area decreases, PLAND value approaches zero.

NP metric (number of patches) indicates the total number of patches. Using this metric, one can work out the number of patches in the landscape or the total number of patches in a particular class. The corollary of landscape disruption is an increase in the number of patches in a type of land cover. Therefore, comparing the numbers of patches over the years is helpful in examining landscape disruption.

AREA_AM metric (Mean Patch Size) measures either mean patch size in land cover class or mean patch size in the whole landscape in hectares. By examining the changes of this metric in a particular landscape over the years, we can identify landscape disruption. Forman argues that patch size affects biomass, primary productivity, nutrient storage per unit area, and composition and diversity of species [20]. Accordingly, as the mean size of natural patch gets smaller or as the mean size of man-made patches, such as impervious surfaces, gets bigger, many of the processes might not happen and biodiversity might, therefore, be threatened.

GYRATE metric (Radius of Gyration) is a metric that measures the average distance between the center of a patch and the outmost extent of its contiguous cells (i.e., a patch). As a measure of landscape configuration, GYRATE is essentially concerned with spatial properties and demonstrates the scope of a patch expansion along the landscape. In equal conditions, bigger patches have greater values in this metric. In other words, in patches of equal areas, long and extended patches have greater radii of gyration. Through the use of this metric, landscape connectivity is measured.

ENN metric (Euclidean Nearest Neighbor Distance) measures the shortest distance from one patch to another patch of the same type. It refers to the relative locations of patches. ENN could describe the spatial distribution of patches of a particular type and how they have changed over the time. For instance, the development of man-made patches (e.g., city) in a landscape increases the distance between other natural patches.

In this study, FRAGSTATS software [19] was used in order to compute landscape metrics in time scale of the research.

\section{Results}

In class level, computation of the metrics in the class of impervious surfaces is described in Table 1 and illustrated in Figure 6.

The results indicate that during the period of study, the CA metric of impervious surfaces has increased from 5478 in 1976 to 19548 in 2005. This means that it has quadrupled in less than 30 years while the population of the area has tripled in this period of time. The results of the two projection scenarios show a descending trend for both scenarios, which means the increasing amount and connectivity of impervious surfaces in landscape. This descending trend will be greater in the current growth scenario.

PLAND metric shows that in 1976, impervious surfaces constituted $2.5 \%$ of the entire region and reached $9 \%$ in 2005 . Noting that surfaces with a slope of $20 \%$ and impassable rocky regions constitute nearly $50 \%$ of the region, the increase in impervious surfaces has entirely happened in agricultural regions or other types of land covers such as wetlands. At this period of time, the area of wetlands has decreased from $3 \%$ to less than $1 \%$ and the area of farmlands and open spaces has decreased from $44 \%$ to $39 \%$. The results of the two projection scenarios also indicate that impervious surface area will reach 9.3 in smart urban growth scenario and 12.23 in current growth scenario and it will 

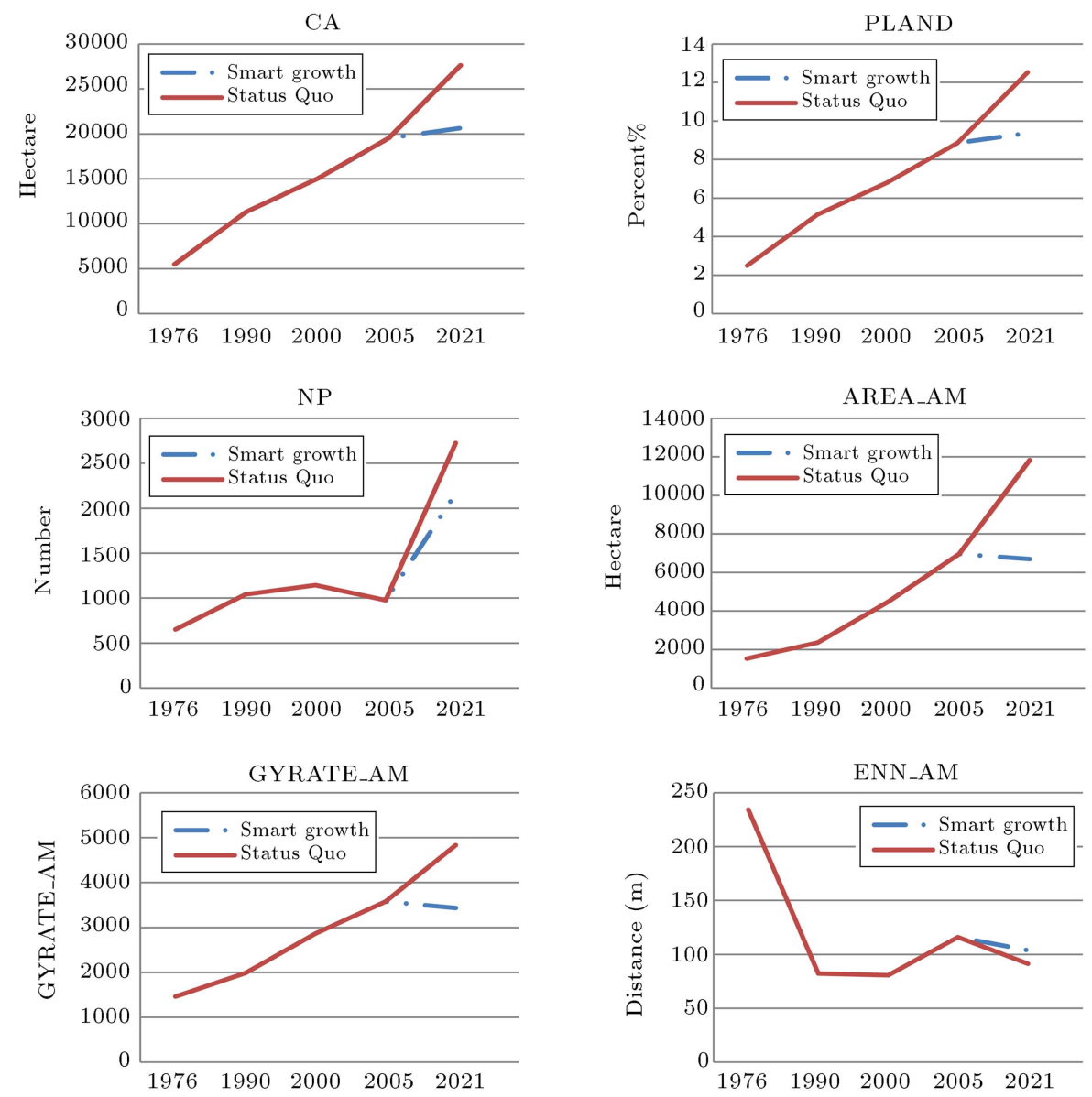

Figure 6. Results of measuring landscape metrics in class level for different years.

exceed $10 \%$ of basin threshold where negative ecological impacts begin.

With respect to NP metric, as it is described in Figure 6, the number of patches initially had an ascending trend and from the year 2000 onwards, it has exhibited a descending trend. This has happened due to filling of empty spaces between impervious surfaces and continuity between these surfaces as a result of city growth. Also, other metrics such as AREA_AM and GYRATE substantiate the phenomenon. The results of the two projection scenarios also indicate that the number of patches in impervious surfaces will reach 2163 in smart growth scenario and 2727 in current growth scenario.

The mean of nearest distance between patches in impervious surfaces from 1976 to 1990 exhibits a descending trend with a steep slope. This metric has not undergone a considerable change between 1990 and 2000 and it demonstrates an increasing trend from 2000 to 2005; this increasing trend denotes that impervious surfaces are being shaped in a greater distance from the old impervious surfaces. The results of the two projection scenarios show a descending trend for both scenarios, which means the increasing amount and connectivity of impervious surfaces in landscape. This descending trend will be greater in the current growth scenario.

Considering these results, it can certainly be stated that for both urban scenarios, the related metrics show only little difference for future development and mainly represent the final spatial configuration of urbanized land. Only in the smart growth scenario, spatial metrics show a better composition and configuration of natural lands, because the smart growth strategy is to protecting all open spaces such as farmland and wetlands, concentrating urban development near the old urban area and preventing road construction to minimize fragmentation of natural landscapes.

\section{Conclusion}

In this research, we explored a framework to integrate remote sensing, spatial metrics, and urban growth modeling, aiming to apply resilient thinking to support urban planning and management in Shiraz urban region. This integration is the strong point of this research. Based on our knowledge, a few studies have combined remote sensing, spatial analysis, and modeling in a comprehensive framework for applying resilient thinking in urban planning and management. 
With respect to the studies in this paper, it can be concluded that the expansion of impervious surfaces, as a result of city growth and expansion of transportation networks, has impacts on natural lands and farmlands. In competing with urban functions, natural and agricultural functions are often eliminated or adjusted, resulting in serious problems for biodiversity. Transportation networks separate natural lands which were once connected and spread pollution throughout the landscape. It will be clearly noticeable in urban region of Shiraz that temporal and spatial dynamics of spatial metrics are analyzed. The patterns of impervious surfaces have undergone major changes over the past three decades in Shiraz and farmlands and natural lands have been precipitously covered by impervious surfaces, particularly between 1976 and 1990. Expansion of impervious surfaces has resulted in destruction of wetlands and farmlands and disruption of habitats. Not surprisingly, the continuation of such trend will cause complete destruction of Shiraz ecological support system and threaten human welfare. Furthermore, by comparing current growth scenario and smart growth scenario using imperviousness index and landscape metrics, it is discovered that smart growth scenario will have fewer impacts on ecological health and resiliency of the urban region. Smart growth scenario takes the maintenance of the quality of urban life into consideration and uses land efficiently to develop habitats as well. In this scenario, not only compressing city growth will be focused, but also, by increasing residential density in cities, urban lands will be allocated to develop other uses of land such as green spaces. In this paper, by employing Remote Sensing (RS), imperviousness index, and landscape metrics, it became clear that these instruments can provide planners with sufficient information in understanding landscape dynamics and in monitoring the changes of land. Modeling and simulation of future urban growth scenarios also appear to be useful in predicting and assessing the effects of each scenario on ecological resilience of the urban region.

\section{References}

1. United Nation Department of Economic and Social Affairs/Population Division, World Population Prospects: The 2007 Revision, United Nations publication, www.unpopulation.org (2008).

2. Alberti, M. and Marzluff, J.M. "Ecological resilience in urban ecosystems: Linking urban patterns to human and ecological functions", Urban Ecosystems, 7, pp. 241-265 (2004).

3. Arnold, C.L. and Gibbons, C.J. "Impervious surface coverage: The emergence of a key environmental nidicator", Journal of the American Planning Association, 62(2), pp. 243-258 (1996).
4. Grimm, N.B., Grove, J.M., Pickett, S.T. and Redman, C.L. "Integrated approaches to long-term studies of urban ecological systems", BioScience, 50, pp. 571-584 (2000).

5. Fazal, S. "The need for preserving farmland: A case study from a predominantly agrarian economy", Landsc. Urban Plan, 55, pp. 1-13 (2001).

6. $\mathrm{Xu}, \mathrm{W}$. "The changing dynamics of land-use change in rural China: A case study of Yuhang, Zhejiang province", Environ. Plan., 36, pp. 1595-1615 (2004).

7. Wilson, B. and Chakraborty, A. "The environmental impacts of sprawl: emergent themes from the past decade of planning research", Sustainability, 5, pp. 3302-3327 (2013).

8. Folke, C., Carpenter, S., Walker, B., Scheffer, M., Elmqvist, T., Gunderson, L. and Holling, C.S. "Regime shifts, resilience, and biodiversity in ecosystem management", Annual Review of Ecology, Evolution, and Systematics, 35, pp. 557-581 (2004).

9. Adjer, W., Hoghes, T., Folke, C., Carpenter, S. and Rockstorm, J. "Social ecological resilience to coastal disasters", Science, 309(5737), pp. 1036-1039 (2005).

10. Wikström, A. "The challenge of change: planning for social urban resilience An analysis of contemporary planning aims and practices ", Master's Thesis in Urban and Regional Planning, Department of Human Geography, Stockholm University, www.humangeo.su.se (2013).

11. Walker, B. and Salt, D., Sustaining Ecosystems and People in a Changing World, Island press, Washington, USA (2006).

12. Chakraborty, A., Kaza, N., Knaap, G.J. and Deal, B. "Robust plans and contingent plans: The promise of scenario planning", J. Am. Plan. Assoc., 77, pp. 251266 (2011).

13. Heink, U. and Kowarik, I. "What are indicators? On the definition of indicators in ecology and environmental planning", Ecological Indicators, 10(3), pp. 584-593 (2010).

14. Botequilha, L. and Ahren, J. "Applying landscape ecological concepts and metrics in sustainable landscape planning", Landscape and Urban Planning Island Press, 59(2), pp. 65-93 (2002).

15. Smart Growth Network (SGN). http://www.smartgrowth.Org (2015).

16. Statistical center of Iran, National Population and Housing Census in Iran, publication of Statistical center of Iran, Iran (2014).

17. Johnston, RA.D., Shabazian, D. and Gao, S. "UPlan: A versatile urban growth model for transportation planning", Transportation Research Record, 1831, pp. 202-209 (2003).

18. Makhdoum, M.F. Darvishsefat, A.A. Jafarzadeh, H. and Makhdoum, A.F. "Environmental evaluation and planning by geographic information system", Tehran university publication, Tehran, Iran (2002). 
19. Mcgarigal, K. and Mark, J., Fragstats Spatial Pattern Analysis Program for Quantifying Landscape Structure Reference Manual, Oregon State University, Oregon, USA (1995).

20. Forman, R.T.T. and Godron, M., Landscape Ecology, John Wily \& Sons, New York, N.Y, USA (1986).

\section{Biographies}

Ahad Sotoudeh is a researcher and lecturer in the field of Environmental Planning. He received his $\mathrm{PhD}$ degree in Environmental Planning from University of Tehran, in 2010. He is currently an Assistant Professor in the Department of Environmental Engineering at Yazd University. His research interests include envi- ronmental impact assessment of development projects, urban ecological planning, and ecological impacts of climate change.

Parastoo Parivar received her $\mathrm{PhD}$ degree in Environmental Planning from Tehran University, Iran, in 2013, and is currently lecturer of Environmental Science in the Department of Environment, Faculty of Natural Resources, at Yazd University, Yazd, Iran. Her coursework focuses on urban environmental assessment and planning. She has served as an environmental consultant in urban planning projects. Her research interests include urban ecological planning and design, ecological risk assessment, and environmental assessment. 